Portland State University

PDXScholar

Spring 12-13-2013

\title{
Factors Influencing Youth Self-Perceptions of Overweight and Obesity
}

\author{
Caitlin Helen Sommers \\ Portland State University
}

Follow this and additional works at: https://pdxscholar.library.pdx.edu/open_access_etds

Part of the Health Psychology Commons, and the Public Health Commons Let us know how access to this document benefits you.

\section{Recommended Citation}

Sommers, Caitlin Helen, "Factors Influencing Youth Self-Perceptions of Overweight and Obesity" (2013). Dissertations and Theses. Paper 1484.

https://doi.org/10.15760/etd.1483

This Thesis is brought to you for free and open access. It has been accepted for inclusion in Dissertations and Theses by an authorized administrator of PDXScholar. Please contact us if we can make this document more accessible: pdxscholar@pdx.edu. 
Factors Influencing Youth Self-Perceptions of Overweight and Obesity

by

Caitlin Helen Sommers

A thesis submitted in partial fulfillment of the requirements for the degree of

Master of Science

in

Health Studies

Thesis Committee:

Gary Brodowicz, Chair

Belinda Ziedler

Randy Miller

Portland State University

2013 
(C) 2013 Caitlin Helen Sommers 


\begin{abstract}
This study sought to examine whether participation in physical activity affects the ability to correctly classify body size, based on body mass index classifications. Secondarily, this study determined whether adolescents who incorrectly classified their body size overestimated or underestimated their size. Self-report data from the Youth Risk Behavior Surveillance Survey collected by the Centers for Disease Control and Prevention were analyzed. Logistic regression was performed to examine relationships between self-perception of body size and physical activity, television viewing time, computer/video game use, physical education class time, and extracurricular sports activities. Significance was set to $\mathrm{p}<0.05$. Physical activity was the only statistically significant independent variable $(\mathrm{p}=0.058, \mathrm{OR}=1.060)$. Although physical activity was shown to be statistically significant, it did not appear to meaningfully increase the ability of youth to correctly classify body size. Secondary analysis showed that adolescents who incorrectly classified their body size were more likely to underestimate their body size. Females more frequently underestimated their body size (females=673; males=384).
\end{abstract}


Table of Contents

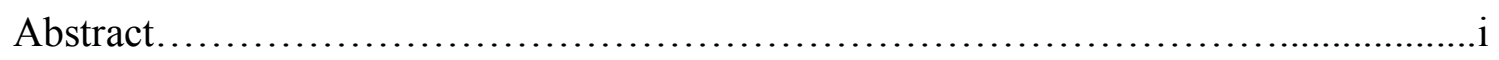

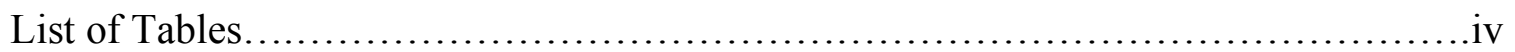

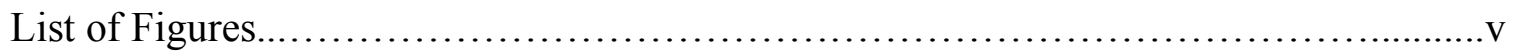

\section{Chapter 1}

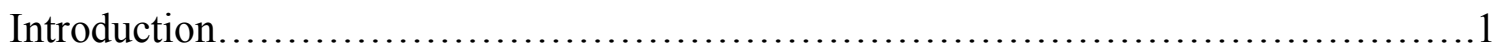

\section{Chapter 2}

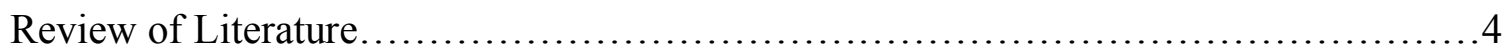

Obesity Rates.....................................................4

Physical Activity and Obesity Rates.....................................4

BMI and Body Image..............................................6

Validity and Reliability of Self-Report Data..............................9

Chapter 3

Methods.....................................................................

Study Design...................................................... 10 
Participants.................................................... 10

Assessment of Height, Weight, and Body Mass Index...................... 11

Assessment of Physical Activity.........................................11

Data Analysis.................................................... 12

\section{Chapter 4}

Results................................................................ 14

Question 1: Association between variables and ability to correctly classify body size................................................ 14

Question 2: Explanation of participants' body size estimations.................14

\section{Chapter 5}

Discussion.............................................................. 17

References............................................................ 20 


\section{List of Tables}

Table 1: Regression analysis results.....................................14 


\section{List of Figures}

Figure 1: Percentage of participants who incorrectly categorized their body size........15

Figure 2: Percentage of participants who correctly categorized their body size. .........16 
Chapter 1

Introduction

"Obesity now affects $17 \%$ of all children and adolescents in the United States triple the rate from just one generation ago" (CDC, 2012). Obesity in youth is defined by the Centers for Disease Control and Prevention (CDC) as having a Body Mass Index (BMI) at or above the $95^{\text {th }}$ percentile for age and sex (CDC, 2011). Recent technological advances have changed the way we interact with our environment. Today's youth have unrestricted access to television, computers, and video games. Instead of sending kids outside to play, parents are allowing them to watch a television show or play a video or computer game until dinner is ready. The CDC (2013) has determined that the rising rates of obesity in youth are the result of eating too many calories and not getting enough physical activity. Not only is there an increased reliance on prepackaged, processed, and fast foods but also the portion sizes are much larger. The average American diet provides 500 kilocalories per day more today than the average American diet provided in the 1970's (Putnam \& Allshouse, 1999). Considering that one pound is equivalent to approximately 3500 kilocalories (Wishnofsky, 1952), 500 extra kilocalories per day equates to one pound extra per week; therefore it is not surprising that the weight of the population is increasing so rapidly.

The increases in obesity rates can lead to increases in significant health problems, both physical and psychosocial. Some health problems may manifest while individuals are still children, and if lifestyle habits do not change, more will appear as they enter adult hood. Obese children are more likely to have high cholesterol and high blood 
pressure, which are both factors of cardiovascular disease (Freedman et al., 2007), increased risk of insulin resistance, impaired glucose tolerance, and type 2 diabetes (Whitlock et al., 2005), breathing problems, joint problems and muscular discomfort (Han et al., 2010), and greater risk of social and psychological problems such as depression and low self-esteem throughout adolescence (Whitlock et al., 2005). Being more likely to become obese adults (Biro et al., 2010), obese children who do not change their habits are at risk of more serious health issues such as diabetes, cardiovascular disease, and some cancers (National Institute of Health, 1998). Additionally, obese children often continue to experience more severe obesity with age (Freedman et al., 2009).

Farhat et al. (2010) analyzed data from a nationally representative sample of students 11 to 17 years old that included height, weight, substance abuse and bullying. They concluded that overweight and obese children are at risk of developing health behaviors of concern, which may lead to both medical and social problems associated with weight. Nollen et al. (2006) suggested that body image impacts adolescents' psychological and physical functioning, and therefore research regarding factors that influence perceptions of body size is needed. The present study is based on data from the National High School Youth Risk Behaviors Surveillance Survey (YRBSS) (CDC, 2011), which asked respondents about various health topics including drug use, alcohol use, sexual health, bicycle safety, nutrition and dieting habits, physical activity, and other health related topics. The survey also asked participants to report their height and weight along with whether they felt their body size was underweight, normal, overweight, or 
obese. The CDC's YRBSS nationally representative sample of youth was used to examine the association between amount of physical activity and ability to correctly classify ones' body size. Specifically, do levels of physical activity, hours of TV viewing time, usage of computers and video games, time spent in physical education classes, and participation in extracurricular sports activities influence one's ability to correctly classify his or her own body size? Secondarily, are those who incorrectly classify their body size more likely to underestimate or overestimate their body size? 
Chapter 2

Review of Literature

\section{Obesity Rates}

In recent years, the rising obesity rates for children and youth have become a topic of many research studies. Wang and Lobstein (2006) suggest that the prevalence of obesity globally is highest in school-aged children and youth. It has been suggested that the obesity rates for youth 12-19 years of age have grown exponentially since the late 1970s (Mahoney et al., 2005, CDC 1999, U.S. Department of Health, 1996). The actual obesity rates from a 1999 study by the CDC show rates have nearly tripled between the late 1970s and 1999, while a 2001 study conducted by the U.S. Department of Health and Human Services showed that $14 \%$ of $12-19$ year olds are classified as being overweight or obese. More recently, it has been suggested that in the past 15-20 years these percentages have skyrocketed from 18-26 per cent to 39 per cent. Shields (2005) showed the percentage of Canadian children and adolescents classified as overweight or obese to be as high as 26 per cent. Over 30 years ago, Huse et al. (1982) suggested that the percentage of children in the U.S. classified as overweight or obese was as high as 30 per cent. Despite the variability in the reported percentage of overweight or obese children and adolescents, it is clear that the obesity rates have increased significantly over the past four decades.

\section{Physical Activity and Obesity Rates}

Over the past 20 years, there have been many research efforts to determine the factors underlying childhood obesity, and it is often suggested that declining physical activity levels play a significant role. However, recent research suggests that little is 
known about the association of obesity with health risk behaviors, including physical inactivity (CDC, 2007). In the early 1990's, Durnin (1992) stated that children were not as active as they were fifty years prior. Other work has shown that behavioral risk factors for adolescents often occur simultaneously with inadequate diets, physical inactivity, and sedentary lifestyles (Flegel et al., 2002; Harris et al., 2009; Iobst et al., 2009). Biddle et al. (2004) suggest that although there are clear links between activity and health in youth, there is not enough research in this area because the amount of time necessary for disease to manifest as a result of sedentary lifestyles is often much longer than the duration of most existing studies. Biddle et al. (2004) support the need for a greater understanding of physical activity in the youth of America.

The results of studies examining the relationship between obesity and physical activity have been contradictory. Although a review by Steinbeck (2001) suggests a link between inactivity and the development of obesity in children and adolescents, Biddle et al. (2004) found no evidence that physical inactivity is a precursor of obesity in this age group. A physical activity intervention study by Bass (2000) shows very small decreases in adiposity as a result of physical training in youth. Other research has shown that increased levels of activity in children may reduce cardiovascular disease risks and adiposity, and improve bone health (Riddoch, 1998). Multiple studies have shown that not only has energy expenditure in children decreased over the past 50 years but also this decrease continues into and through adolescence (Kimm et al., 2002; Johnson et al., 2000; Ekelund et al., 2002). Based on guidelines published by the US Surgeon General and the National Association for Sport and Physical Education (2004), it has been 
concluded that at least $50 \%$ of children and adolescents are insufficiently active for health. The guidelines are as follows:

Guideline 1. Children should accumulate at least 60 minutes, and up to several hours, of age-appropriate physical activity on all, or most days of the week. This daily accumulation should include moderate and vigorous physical activity with the majority of the time being spent in activity that is intermittent in nature. Guideline 2. Children should participate in several bouts of physical activity lasting 15 minutes or more each day.

Guideline 3. Children should participate each day in a variety of age-appropriate physical activities designed to achieve optimal health, wellness, fitness, and performance benefits.

Guideline 4. Extended periods (periods of two hours or more) of inactivity are discouraged for children, especially during the daytime hours. (NASPE, 2004)

In another study, it has been suggested that there might be genetic links to the increasing obesity rates. However, Goran and Treuth (2001) argue that it is unlikely that changes to the gene pool can account for the increased prevalence of obesity. Changes to the environment, including reliance on high-fat fast foods, technology and energy-saving devices have also been postulated to play a significant role. It is more likely that the increase in obesity rates is due to changes in diet and physical inactivity than it is to large-scale genetic changes in society. Review of the current literature suggests that finding an appropriate measure of body weight for youth, and an accurate way to determine activity levels are important for addressing the problem of childhood obesity.

\section{BMI and Body Image}

Farhat et al. (2010) argue that reliance on self-reported weight and height for calculating BMI as a limitation in studies focusing on childhood obesity. Farhat et al. 
(2010) analyzed data from a nationally representative sample of students aged 11 to 17 years old which included height, weight, and substance abuse and bullying. They concluded that overweight and obese children are at risk of developing health behaviors of concern, which may lead to both medical and social problems associated with weight. Fernandez et al. (1994), and Rolland et al. (1996), suggest it would be useful to incorporate BMI into research on body size perception. In the United States, the CDC (2007) growth charts use BMI percentiles to classify children as normal weight, overweight, and obese. Obesity is classified as a BMI at or above the $95^{\text {th }}$ percentile for gender-specific age and height (Flegel et al., 2002; Harris et al., 2009; Iobst et al., 2009).

Recently, body image in children and adolescents has been a popular research topic (Gustafson-Larson, \& Terry, 1992). However, a review of the literature demonstrates that there are a very limited number of studies that compare actual body size to perceived body size (Desmond et al., 1989). When examining prevalence rates for obesity, few authors have estimated trends by using objective measurements for height and weight, and have relied heavily on self-report data (Hoelscher et al., 2004; Thorpe et al., 2004). However, Goodman et al. (2000) and Deitz et al. (1999) have shown selfreported weight and height are adequate estimates for calculating BMI. Rolland et al. (1996) conducted a review of studies concerned with children's ideas of dieting, and weight control behaviors and concluded that most studies have not examined relationships between actual weight and body image. Wadden et al. (1989) suggested using actual body weight as a control variable for body image studies. Nollen et al. (2006) suggested that body image impacts adolescents' psychological and physical functioning, and therefore research regarding factors that influence perceptions of body 
size is needed. In order to obtain valid and reliable results regarding perceptions of body size, the accuracy of perceptions of body size by youth must be examined (Gardner et al., 1999). Gardner and colleagues (1999) state that the knowledge of children's perceptions of their whole body size is limited by the methods that are available for assessing perceptions.

A study by Gardner et al. 1999 is one of the few that have investigated perceptions of body size, and how they change over time. Data were collected on children between six and 12 years of age over three years. The data included height, age, weight, and body mass index. After initial data collection, children were shown video images or static life-size images of themselves that had been distorted to be too wide or too thin. The children were then asked to adjust the image to reflect their own body size. The researchers concluded that children 12 years of age and older were accurate in estimating their body size, and there was a decrease in the variance over three successful years of data collection.

Field and colleagues (2001) have identified family, peers, and media as factors contributing to self-perceptions of body size. Potter et al. (2004) show that adolescents who begin to engage in negative health behaviors (e.g., smoking) to control their weight may have negative body image. Finally, Rierdan, and Koff (1997) suggest that mood and depression symptoms may also be factors in appropriate perceptions of body size.

In 2010, Duncan and colleagues conducted a study to determine if there was a connection between weight perceptions, body fatness, and weight control in adolescent girls. The researchers sampled 954 girls 11-15 years old to collect data on BMI, weight control, weight perception, and body fatness. The results showed that there was a high 
level of misclassification across all levels of body fatness, and that participants who were trying to lose weight tended to use dieting and exercise as their primary tools for weight loss. The results specific to exercisers show that $81 \%$ of participants were classified as normal weight while only $62 \%$ classified themselves as normal weight and $31 \%$ classified themselves as overweight.

\section{Validity and Reliability of Self-Report Data}

Himes and Faricy (2001) state that self-reported height and weight are cost effective, logistically attractive alternatives to direct measurements. At this time, there have been relatively few studies that have used self-report techniques, and these studies have had small sample sizes or specialized populations (Brooks-Gunn et al., 1987; Fortenberry, 1992; Hauck et al., 1995). Himes and Faricy (2001) also suggest that selfreported weight is often more valid than self-reported height; however, the validity varies considerably with age. For example, the 12 to 13 year old age group had the highest frequency of missing data. This was expressed by Himes and Faricy (2001) as being a concern for this population being representative of the population as a whole, thereby limiting the extent to which data obtained from children under the age of 14 years old can be used (i.e., limited external validity). Therefore, self-reported height and weight should not be routinely collected for youth younger than 14 years of age. 
Chapter 3

Methods

\section{Study Design}

Data were obtained from the 2011 Youth Risk Behaviors Surveillance Survey (YRBSS) (CDC, 2011). The CDC created the biennial YRBSS in 1991 to collect data related to the risk behaviors that contribute to the leading causes of morbidity and mortality in youth and young adults (Brener et al., 2013). YRBSS data are collected to create a representative sample of U.S. youth between grades nine and 12 who attend both public and private school in the 50 states and the District of Columbia.

Procedures for the survey were designed to provide confidentiality for the students by allowing anonymous and voluntary participation (CDC, 2011). Parental permission procedures were followed based on local guidelines. In the 2011 data collection, $10 \%$ of participating schools used active permission methods. In this method, parents must return a signed approval form to the school before their child can participate. The other $90 \%$ of the schools in the 2011 data collection used passive permission. In this method, parents only send a signed form back if they do not want their child to participate. Surveys were administered during one class period and results were recorded by students directly onto a computer-readable booklet or answer sheet.

\section{Participants}

In the 2011 survey, the school response rate was $81 \%$, and the overall response rate was $71 \%(C D C, 2011)$. The total number of respondents was 10,598 . The sample for the current study included only those students who self-reported as being age 15 . This 
age was selected based on research by Himes and Faricy (2001) suggesting that selfreport data on stature and weight should not be collected regularly for children under the age of 14 due to higher rates of non-response in the lower age categories. The sample included 4062 students. In the current study, 2010 (49.5\%) participants were female with an average height of $1.68 \mathrm{~m}$, an average body mass of $66.2 \mathrm{~kg}$, and an average body mass index of $23.4 \mathrm{~kg} / \mathrm{m}^{2}$ and $2052(50.5 \%)$ were male with an average height of $1.70 \mathrm{~m}$, an average body mass of $68.3 \mathrm{~kg}$ and an average body mass index of $23.5 \mathrm{~kg} / \mathrm{m}^{2}$.

\section{Assessment of Height, Weight, and Body Mass Index}

Height was self-reported in feet and inches in question 6 "How tall are you without your shoes on?" Weight was self-reported in pounds in question 7 "How much do you weigh without your shoes on?" Body Mass Index (BMI) was calculated after unit conversion using the formula $B M I=\mathrm{kg} / \mathrm{m}^{2}$. Based on recommendations from the Expert Committee on the Assessment, Prevention, and Treatment of Child and Adolescent Overweight and Obesity convened by the American Medical Association (AMA), "overweight" is classified as a BMI at or above the $85^{\text {th }}$ percentile and below the $95^{\text {th }}$ percentile, and "obese" is classified as a BMI at or above the $95^{\text {th }}$ percentile (CDC, 2011). Any BMI at or above the $5^{\text {th }}$ percentile and below the $85^{\text {th }}$ percentile is classified as "normal weight", and below the $5^{\text {th }}$ percentile is classified as "underweight". Percentiles are specific to age and sex based on the "SAS Program for the 2000 CDC Growth Charts" developed by the CDC's Division of Nutrition, Physical Activity, and Obesity (CDC, 2011).

\section{Assessment of Physical Activity}

Physical activity was measured by self-reported answers to the questions: 
1. "During the past 7 days, on how many days were you physically active for a total of at least 60 minutes per day?"

2. "In an average week when you are in school, on how many days do you go to physical education (PE) classes?"

3. "During the past 12 months, on how many sports teams did you play?"

4. "On how many of the past 7 days did you do exercises to strengthen or tone your muscles, such as push-ups, sit-ups, or weight lifting?"

\section{Data Analysis}

All statistical analyses were performed using SPSS (version 18.0). Logistic regression was used to examine the association between classification of body size (dependent variable) and physical activity, TV time, video game and computer usage, P.E. class hours, and extracurricular activities (independent variables). The regression analysis involved entering all independent variables simultaneously.

To further examine participants' classifications of body size, data were sorted according to correct and incorrect classification of body size. Data for those who incorrectly classified their body size were further examined to determine if they underestimated their true body size classification (i.e., normal weight classifying as underweight; overweight classifying as underweight; and obese classifying as underweight, normal weight, or overweight). Overestimations of true body size were also examined (i.e., overweight classifying as obese; normal weight classifying as overweight or obese; and underweight classifying as normal, overweight, or obese). Finally, the subsample of participants who incorrectly classified was separated into male 
and female subgroups, and a Chi-Square analysis was run to determine whether a gender difference existed in the frequency of over/underestimation of body size. 
Chapter 4

Results

Question 1: Association between variables and ability to correctly classify body size.

Table 1 shows the results of the logistic regression analysis.

Table 1. Regression analysis results

\begin{tabular}{|c|c|c|c|}
\hline & $\mathrm{B}$ & Sig. & $\operatorname{Exp}(B)$ \\
\hline Physical Activity & .058 & $<.001$ & 1.060 \\
\hline TV Hours & -.031 & .096 & .970 \\
\hline Video or Computer Usage & -.031 & .083 & .970 \\
\hline P.E. Class & .006 & .690 & 1.006 \\
\hline Team Participation & .043 & .208 & 1.044 \\
\hline Constant & .042 & .731 & 1.043 \\
\hline
\end{tabular}

Physical activity, although statistically significant $(\mathrm{p}<0.001)$, did not meaningfully increase the ability to predict whether body size can be correctly perceived by youth; Table 1 shows that the odds ratio was only 1.060. All other variables in the model were not statistically significant.

\section{Question 2: Explanation of participants' body size estimations.}

Figure 1 shows the percentage of participants who incorrectly classified their body size. 


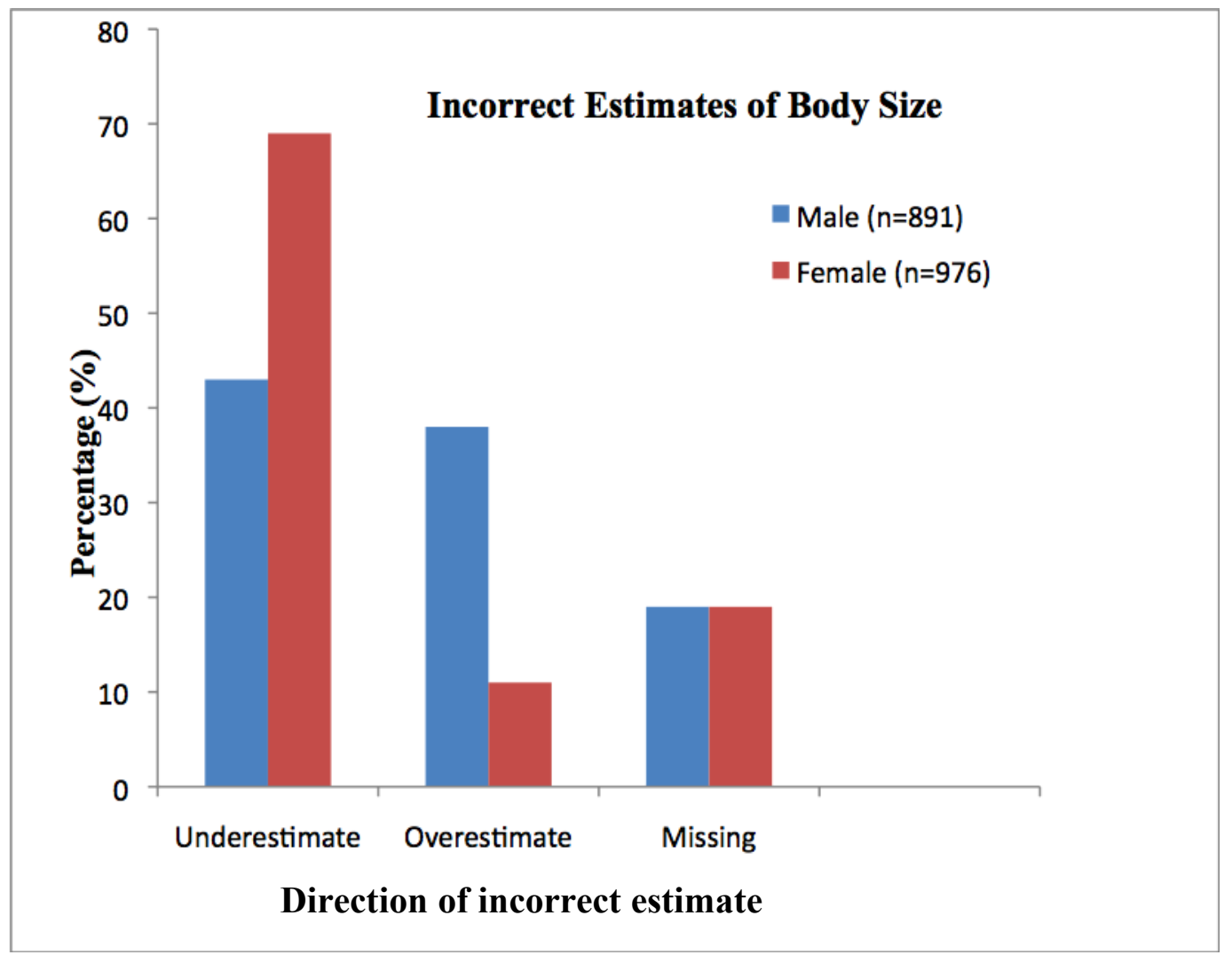

Figure 1. Percentage of participants who incorrectly categorized their body size.

Of the participants who incorrectly classified their body size, $42 \%$ of males underestimated, $30 \%$ of males overestimated, and $19 \%$ of males were missing information. In comparison, $69 \%$ of females underestimated, $12 \%$ of females overestimated, and $19 \%$ of females had missing data.

Figure 2 shows the percentage of male and female participants who correctly classified their body size. Of the participants who correctly classified their body size, $51 \%$ were normal weight, $12 \%$ were overweight, $4 \%$ were obese, and $2 \%$ were underweight. 


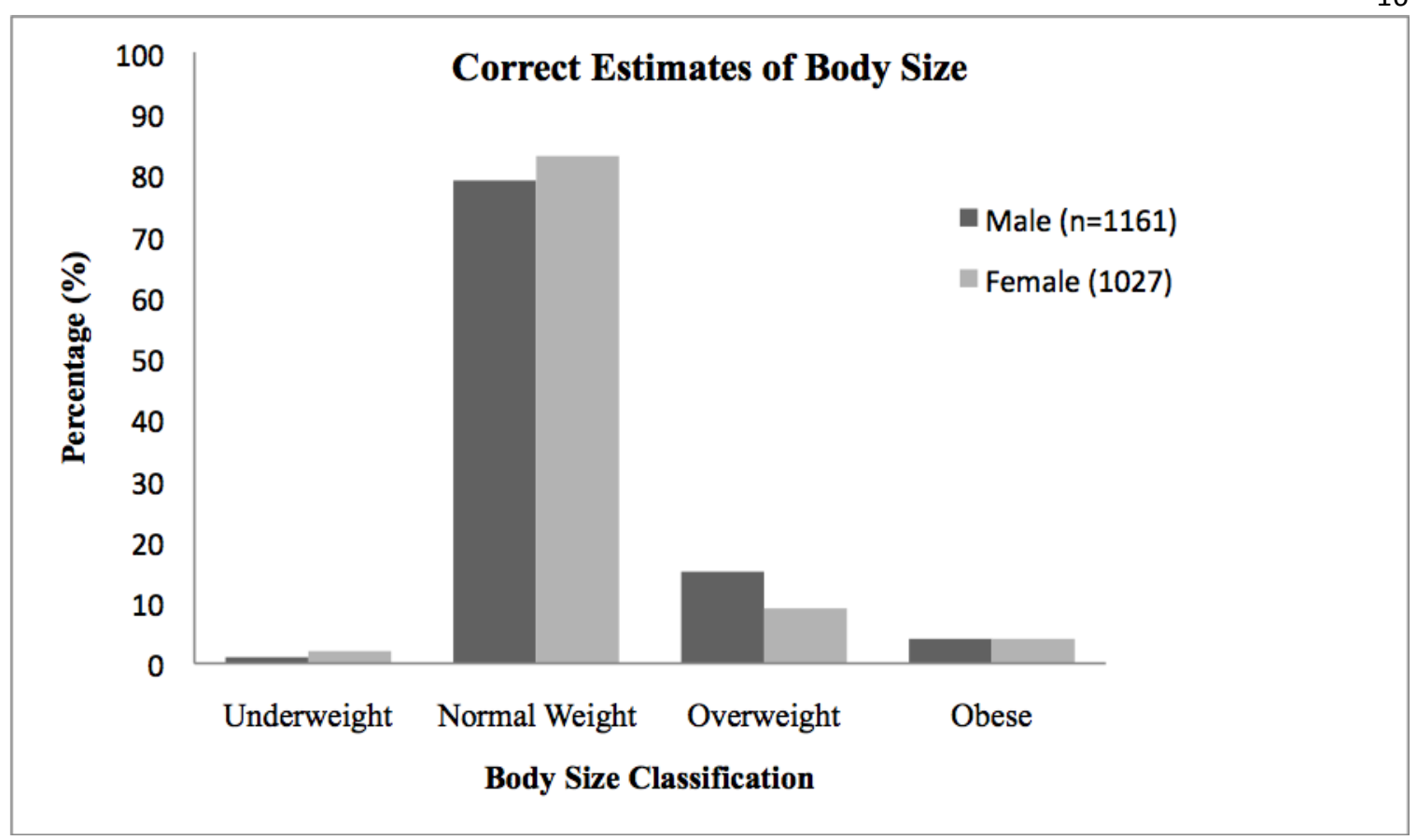

Figure 2. Percentage of participants who correctly categorized their body size.

Finally, a Chi-Square analysis was performed to examine whether males and females differed in their misclassification direction (underestimate/overestimate), The Chi-Square value of 196.7 was statistically significant $(\mathrm{p}<0.01)$. The data show that while males underestimated and overestimated their body size about equally, females underestimated their body size more frequently than they overestimated. 
Chapter 5

Discussion

\section{Discussion}

Due to the increase in obesity rates around the world, it is important that adolescents are able to recognize signs of increased body size as well as the health implications increased body size may have so they can make better decisions for their health in the future. It is important to note that the majority of participants who incorrectly classified their body size underestimated. Adolescents should be made aware of what a "healthy" size is and by improving their ability to assess their own body size, they may be able to make lifestyle adjustments. The finding that physical activity did not appear to have a more substantial impact on individual ability to correctly classify body size is surprising, because Duncan et al. (2010) reported different results in their investigation of exercise for weight loss and perception of body size in adolescent (11-15 year old) girls. The results may be dissimilar because Duncan's research included only females, whereas the current study included both genders. It is also possible that in Duncan's study the values were obtained by measuring exercise geared toward weight loss, and not simply physical activity. The other notable difference was that more participants in the study of Duncan et al. (31.4\%) estimated their body size to be classified as overweight. In the current study, of the participants who incorrectly classified themselves, over $50 \%$ classified themselves as underweight.

\section{Limitations}

The limitations of this study revolve primarily around the use of self-reported data. The use of self-report questions for the assessment of physical activity may not 
give a complete portrayal of the level of physical activity. For example, it is unknown to what extent the activity reported by participants was light, moderate, or vigorous intensity. Finally, the question regarding in-school physical education classes may not accurately reflect the amount of time students were active during class time.

After review of the questionnaire itself, further development of questions relating to physical activity should take place. On this specific version of the questionnaire, respondents were not asked to indicate the intensity of their $60+$ minutes per day of activity (i.e., low, moderate, or vigorous). Furthermore, when asked about sports teams they were not asked to indicate the sports nor the level of competition.. This could be problematic, because of the variation in actual activity. For example, baseball is characterized by a significant amount of time spent sitting in the dugout, while soccer requires players to spend more time being physically active. The question regarding P.E. class hours per week has similar limitations; it does not differentiate between active and inactive class time. With more in-depth questions, the self-reported activity levels could provide more precise estimates of physical activity.

Without having measured values for weight and height, the BMI data used to classify the youth in this sample cannot be viewed as completely accurate. Measured height and weight would eliminate this as a limitation. Although it is understood that percentile values for BMI are used more frequently in studies involving youth, it may be beneficial to those viewing the data sets to see actual BMI values next to the BMI percentile rankings in order to draw a comparison as to what someone with a BMI in the $92^{\text {nd }}$ percentile looks like compared to someone with a BMI in the $50^{\text {th }}$ percentile. 
Finally, the sample used for this study was relatively small, although it was derived from a nationally representative sample. A larger sample size that includes data collected from each state would enhance the generalizability of the results.

\section{Conclusions}

The primary purpose of this study was to determine whether higher levels of physical activity, increased hours of TV viewing time, increased usage of computers and video games, more time spent in physical education classes, and increased extracurricular activities increase one's ability to correctly classify his or her own body size. A secondary purpose was to examine, whether those who incorrectly classify their body size are more likely to under or overestimate their body size. After categorizing the data, and analyzing the results, we conclude that higher levels of physical activity do not increase the ability of youth to correctly classify his or her own body size. Although statistically significant in our logistic regression model, the odds ratio indicates that for every one unit increase in physical activity, the odds of correctly classifying body size increases by a factor of 1.06 times.

Additionally, as shown in Figure 1, those who incorrectly classified their body size were more likely to underestimate than to overestimate. And as shown in Figure 2 those who correctly classify their weight were more likely to be normal weight.

\section{Further Research}

Further research on the relationships between physical activity, obesity rates, and the ability to correctly classify body size is warranted. Perception of body size is related to body image, which in turn is related to self-esteem and depression (Rierden \& Koff, 
1997). In order to move toward interventions in both the school and public health sectors, research needs to be conducted that develops a better understanding of the factors that contribute to negative body image and the other associated negative health behaviors. By determining factors related to adolescents' to have an accurate understanding of their own body size, interventions may be developed that can help decrease negative health behaviors. 
References

1. Bass, S. (2000). The prepubertal years: a unique opportune stage of growth when the skeleton is most responsive to exercise? Journal of Sports Medicine, 30, 73-78.

2. Biddle, S., Gorely, T., \& Stensel, D. (2004). Health-enhancing physical activity and sedentary behavior in children and adolescents. Journal of Sports Sciences, 22, $679-701$

3. Biro, F., \& Wien, M. (2010). Childhood obesity and adult morbidities. American Journal of Clinical Nutrition, 91(5), 1499S-1505S.

4. Brener, N., Mcmanus, T., Galuska, D., Lowry, R., \& Weschsler, H. (2003). Reliability and validity of self-reported height and weight among high school students. Journal of Adolescent Health, 32(4), 281-287.

5. Brooks-Gunn, J., Warren, M., Rosso, J., \& Gargiulo, J. (1987). Validity of self- report measures of girls' pubertal status. Child Development, 58, 829-841.

6. CDC. (2007) Youth risk behaviors surveillance. Morbidity and Mortality Weekly Report, 57(1), 1-131

7. Centers for Disease Control and Prevention, National Center for Health Statistics Prevalence of overweight among children and adolescents. Available at http://www.cdc.gov/nchs/products/pubs/pubd/hestats/overwght99.htm accessed 22 April, 2013.

8. Centers for Disease Control and Prevention, Division of Nutrition, Physical Activity, and Obesity. (2011, September13). About BMI for children. Retrieved from http://www.cdc.gov/healthyweight/assessing/bmi/childrens_bmi 
9. Centers for Disease Control and Prevention, Division of Nutrition, Physical Activity, and Obesity. (2012, April 27). Childhood Overweight and Obesity. Retrieved from http://www.cdc.gov/obesity/childhood/

10. Centers for Disease Control and Prevention, Division of Nutrition, Physical Activity, and Obesity. (2013, April 17). A growing problem. Retrieved from http://www.cdc.gov/obesity/childhood/problem.html

11. Centers for Disease Control and Prevention (2011). Youth Risk Behaviors Surveillance Survey. [Data file] Retrieved from http://www.cdc.gov /healthyyouth/yrbs/data/index.htm

12. Desmond, S., Hallinan, C., Price, J., \& Smith, D. (1989). Black and white adolescents' perceptions of their weight. Journal of School Health, 59(8), 353.

13. Dietz, W., \& Bellizzi, M. (1999). Introduction: the use of body mass index to assess obesity in children. American Journal of Clinical Nutrition, 70(1), 123S-125S.

14. Division of Nutrition, Physical Activity and Obesity, National Center for Chronic Disease Prevention and Health Promotion. (2012). Overweight and Obesity: A Growing Problem. Retrieved from http://www.cdc.gov/ obesity/childhood/ problem.html

15. Duncan, J., Duncan, E., \& Schofield, G. (2010). Associations between weight perceptions, weight control, and body fatness in a multiethnic sample of adolescent girls. Public Health Nutrition, 14(1), 93-100.

16. Ekelund, U, Aman, J., \& Yngve, A. (2002). Physical activity but not energy expenditure is reduced in obese adolescents: a case-control study. American Journal of Clinical Nutrition, 76, 935-941. 
17. Farhat, T., Iannotti, R., \& Simons-Morton, B. (2010). Overweight, obesity, youth, and health-risk behaviors. American Journal of Preventive Medicine, 38(3), 258-267.

18. Fernandez, E., Probst, M., Meermann, R., \& Vandereycken, W. (1994). Body estimation and body dissatisfaction in eating disorder patients and normal controls. International Journal of Eating Disorders, 16, 307-310.

19. Field, A., Camargo, C., Taylor, C., Berkey, C., Roberts, S., \& Colditz, G. (2001). Peer, parent, and media influences on the development of weight concerns and frequent dieting among preadolescent and adolescent girls and boys. Pediatrics, 107(1), 54-60.

20. Flegal, K., Wel, R., \& Ogden, C. (2002). Weight-for-stature compared with body mass index-for-age growth charts for the United States from the Center for Disease Control and Prevention. American Journal of Clinical Nutrition, 75, 761-766.

21. Fortenberry, J. (1992). Reliability of adolescents' reports of height and weight. Journal of Adolescent Health, 13, 114-117.

22. Franko, D., \& Striegel-Moore, R. (2002). The role of body dissatisfaction as a risk factor for depression in adolescent girls: is the difference black and white? Journal of Psychosomatic Research, 53(5), 975-983.

23. Freedman DS, Mei Z, Srinivasan SR, Berenson GS, Dietz WH. (2007) Cardiovascular risk factors and excess adiposity among overweight children and adolescents: The Bogalusa Heart Study. Journal of Pediatrics. 150(1), 1217. 
24. Gardner, R., Friedman, B., Stark, K., \& Jackson, N. (1999). Body size estimations in children six through fourteen: A longitudinal study. Perceptual and Motor Skills, 88, 541-555.

25. Goodman, E., Hinden, B., \& Khandelwal, S. (2000). Accuracy of teen and parental reports of obesity and body mass index. Pediatrics, 106(1), 52-58.

26. Goran, M., \& Treuth, M. (2001). Energy expenditure, physical activity, and obesity in children. Pediatric Clinics of North America, 48, 931-935.

27. Gustafson-Larson, A., \& Terry, R. (1992). Weight-related behaviors and concerns of fourth-grade children. Journal of the American Dietetic Association, 92, 818822.

28. Han, J., Lawlor, D., \& Kimm, S. (2010). Childhood obesity. Lancet, 275(9727) 1737-1748.

29. Harris, J., Bargh, J., \& Brownell, K. (2009). Priming effects of television food advertising on eating behavior. Health Psychology, 28, 404-413.

30. Hauck, F., White, L., Cao, G., Woolf, N., \& Strauss, K. (1995). Inaccuracy of selfreported weights and heights among American Indian adolescents. Annals of Epidemiology, 5, 386-392.

31. Himes, J., \& Faricy, A. (2001). Validity and reliability of self-reported stature and weight of US adolescents. American Journal of Human Biology, 13, 255-260.

32. Hoelscher, D., Day, R., Lee, E., Frankowski, R., Kelder, S., \& Ward, J. (2004).

Measuring the prevalence of overweight in Texas schoolchildren. American Journal of Public Health, 94(6), 1002-1008. 
33. Huse, D., Branes, L., \& Colligan, R. (1982). The challenge of obesity in childhood: incidence, prevalence and staging. Mayo Clinic Procedures. 57, 279-284.

34. Iobst, E., Ritchey, P., Nabors, L., Stutz, R., Ghee, K., \& Smith, D. (2009). Children's acceptance of a peer who is overweight: Relations among gender, age, and blame for weight status. International Journal of Obesity, 33, 736-742.

35. Johnson, M., Figueroa-Colon, R, \& Herd, S. (2000). Aerobic fitness, not energy expenditure, influences subsequent increase in adiposity in black and white children. Pediatrics, 106(4), c50.

36. Kimm, S., Glynn, N., \& Kriska, A. (2002). Decline in physical activity in black girls and white girls during adolescence. New England Journal of Medicine, 347, 709-715,

37. Mahoney, J., Lord, H., \& Carryl, E. (2005). After school program participation and the development of child obesity and peer acceptance. Applied Developmental Science, 9(4), 202-215.

38. National Institutes of Health. (1998). Clinical Guidelines on the Identification, Evaluation, and Treatment of Overweight and Obesity in Adults the Evidence Report. Bethesda, MD: National Institutes of health, U.S. Department of Health and Human Services.

39. Nollen, N., Kaur, H., Pulvers, K., Choi, W., Fitzgibbon, M., Li, C., Nazir, N, \& Ahluwalia, J. (2006). Correlates of ideal body size among black and white adolescents. Journal of Youth and Adolescence, 35(2), 293-301. 
40. Politano, G., \& Politano, P. (2011). The obesity epidemic and current perceptions of somatotypes by children. North American Journal of Psychology, 13(3), $349-358$.

41. Potter, B., Pederson, L., Chad, S., Aubut, J., \& Koval, J. (2004). Does a relationship exist between body weight, concern about weight, and smoking among adolescents? An integration of the literature with an emphasis on gender. Nicotine and Tobacco Research, 6(3), 397-425.

42. Putnam, J., \& Allshouse, J. Food consumption, prices, and expenditures. Washington, DC: US Dept of Agriculture, Economic Research Service; 1999. Statistical Bulletin 965.

43. Riddoch, C. (1998). Relationships between physical activity and physical health in young people. In S. Biddle, Cavill ,\& J. Sallis (eds.) Young and Active? Young People and Health-enhancing Physical Activity: Evidence and Implications. Pp 17-48. London: Health Education Authority.

44. Rierden, J., \& Koff, E. (1997). Weight, weight-related aspects of body image and depression in early adolescent girls. Adolescence, 32, 615-624.

45. Rolland, K., Farnill, D., \& Griffiths, R. (1996). Children's perceptions of their current and ideal body sizes and body mass index. Perceptual and Motor Skills, 82, 651-656.

46. Shields, M. (2005). Measured obesity: Overweight Canadian children and adolescents. Available at http://www.statcan.gc.ca/pub/82-620m/2005001/pdf/4193660-eng.pdf accessed 23 April 2013. 
47. Steinbeck, K. (2001). The importance of physical activity in the prevention of overweight and obesity in childhood: a review and opinions. Obesity Reviews 2, $117-130$.

48. Stewart, A., \& Brook, R. (1983). Effects of being overweight. American Journal of Public Health, 73, 171-178.

49. Storz, N., \& Greene, W. (1983). Body weight, body image, and perception of fad diets in adolescent girls. Journal of Nutrition Education, 15, 15-19.

50. Thorpe, L., List, D., Marx, T., May, L., Helgerson, S, \& Frieden, T. (2004).

Childhood obesity in New York City elementary school students. American Journal of Public Health, 94(9), 1496-1500.

51. U.S. Department of Health and Human Services (1996). Physical activity and health: A report of the Surgeon General. Atlanta, GA.

52. Wadden, T., Foster, G., Stunkard, A., \& Linowitz, J. (1989). Dissatisfaction with weight and figured in obese girls: discontent but not depression. International Journal of Obesity, 13, 89-97.

53. Wang, Y., \& Lobstein, T. (2006). Worldwide trends in childhood overweight and obesity. International Journal of Pediatric Obesity. 1, 1, 11-25.

54. Whitlock, E., Williams, E., Gold, E., Smith, P., \& Shipman, S. (2005). Screening and interventions for childhood overweight: a summary of evidence for the US Preventative Services Task Force. Pediatrics, 116(1), 125-144.

55. Wishnofsky, M. (1952). Caloric equivalents of gained or lost weight. Metabolism, 1, 554-555. 